\title{
Anthropogenic Harvesting Pressure and Changes in Life History: Insights from a Rocky Intertidal Limpet
}

\author{
Phillip B. Fenberg ${ }^{1, \star}$ and Kaustuv Roy ${ }^{2}$ \\ 1. Department of Zoology, Oregon State University, Corvallis, Oregon 97331; 2. Section of Ecology, Behavior and Evolution, University \\ of California, San Diego, La Jolla, California 92093
}

Submitted August 30, 2011; Accepted April 20, 2012; Electronically published June 19, 2012

Online enhancements: appendixes. Dryad data: http://dx.doi.org/10.5061/dryad.4rlg2.

\begin{abstract}
AвSTRACT: The importance of large breeding individuals for maintaining the health of marine fish and invertebrate populations has long been recognized. Unfortunately, decades of human harvesting that preferentially remove larger individuals have led to drastic reductions in body sizes of many of these species. Such size-selective harvesting is particularly worrisome for sequentially hermaphroditic species where the larger size classes are composed primarily of one sex. Whether these species can maintain stable sex ratios under sustained harvesting pressure depends on the level of plasticity of their life-history traits. Here, we show that populations of a marine limpet (Lottia gigantea) can adjust a fundamental aspect of their life history (the timing of sex change) when subjected to size-selective harvesting. As predicted by theoretical models, individuals from harvested populations change sex at smaller sizes and grow at slower rates compared to individuals from protected populations. In addition, the relative size at which the change from male to female occurs remains constant $(\sim 0.75$; size at sex change/maximum size) across populations, regardless of harvesting pressure. Our results show that populationlevel demographic and life-history data, in conjunction with existing theory, can be sufficient to predict the responses of sequential hermaphrodites to harvesting pressure. Furthermore, they suggest such species can potentially adapt to size-selective harvesting.
\end{abstract}

Keywords: life-history invariance, Lottia gigantea, size-selective harvesting, relative size at sex change, phenotypic plasticity, protandry.

\section{Introduction}

Size-selective harvesting, in which the larger individuals of a species are selectively caught, has emerged as a major anthropogenic impact on marine species (Fenberg and Roy 2008). By preferentially removing the largest individuals in a population, size-selective harvesting reduces the average body size within populations, thereby affecting many different aspects of the life history and ecology of species (Reznick and Ghalambor 2005; Fenberg and Roy 2008).

* Corresponding author; e-mail: fenbergp@science.oregonstate.edu,
pfenberg@gmail.com.

Am. Nat. 2012. Vol. 180, pp. 200-210. (C) 2012 by The University of Chicago. 0003-0147/2012/18002-53295\$15.00. All rights reserved.

DOI: $10.1086 / 666613$
Size-selective harvesting is particularly worrisome for species in which the large size classes are composed primarily of one sex, as is the case for sequentially hermaphroditic fish and invertebrates. In those species, size-selective harvesting has the potential to drastically skew sex ratios and affect reproductive output (Coleman et al. 1996; McGovern et al. 1998; Alonzo and Mangel 2004; Hawkins and Roberts 2004). Sex allocation theory for sequential hermaphrodites (Warner 1975; Charnov 1982) predicts that size (age) at sex change should be reduced in populations where large adults have high mortality rates in order to compensate for potential impacts on breeding sex ratio. Previous studies have shown that several fish and invertebrate species (two temperate shrimp and one limpet) that are under harvesting pressure do indeed change sex at smaller sizes, supporting the theoretical prediction (Charnov 1981; Cowen 1990; Hannah and Jones 1991; Buxton 1993; Charnov and Hannah 2002; Platten et al. 2002; Hawkins and Roberts 2004; Hamilton et al. 2007; Götz et al. 2008; Rivera-Ingraham et al. 2011).

Theoretical models also make a more specific prediction relating the timing of sex change: the relative size at sex change (size at sex change/maximum size of individuals in the population) should be statistically invariant across species and populations (Charnov and Skúladóttir 2000; Gardner et al. 2005; Linde and Palmer 2008). The observation that slopes of log-log plots of size at sex change (length at which the probability of being the second sex is $\left.0.50 ; L_{50}\right)$ and maximum body size $\left(L_{\max }\right)$ do not significantly differ from unity has been taken to support this hypothesis (Charnov and Skúladóttir 2000; Allsop and West $2003 a, 2003 b$ ). However, others have questioned the validity of such regression-based tests and demonstrated that a slope of unity, by itself, may not necessarily imply invariance (Cipriani and Collin 2005; Nee et al. 2005; but see Linde and Palmer 2008). Perhaps more importantly, the original model describing invariance of size at sex change was formulated based on the life history of a tem- 
perate shrimp species (Charnov and Skúladóttir 2000), not necessarily as an explanatory theory for the timing of sex change across all sequentially hermaphroditic species (Allsop and West 2003a, 2003b). Yet subsequent tests of this hypothesis have focused on the natural variations across species, variations that have evolved over much longer time. So, it remains unclear whether such invariance holds even when $L_{\max }$ is reduced substantially by sizeselective harvesting within a relatively short time period (i.e., a few generations). From a conservation and management perspective, the latter would not only provide evidence for considerable plasticity of this aspect of life history under exploitation pressure but would also allow us to better predict population-level consequences of sizeselective harvesting.

Because of the controversy surrounding the use of regression slopes alone to test life-history invariants (Cipriani and Collin 2005; Gardner et al. 2005; Nee et al. 2005; Linde and Palmer 2008; Molloy et al. 2010), simply comparing $\log$-log plots of $L_{50}$ and $L_{\max }$ of harvested and protected populations is not sufficient to establish whether relative size at sex change can be invariant in response to harvesting pressure. A more detailed analysis that also includes other relevant parameters is needed (Nee et al. 2005; Munday et al. 2006; Savage et al. 2006). This study represents the first in-depth analysis of the sex change invariance hypothesis within a species by using estimates of individual parameters involved (e.g., size/age structure, growth rates, mortality) rather than relying exclusively on $\log$-log plots of $L_{50}$ by $L_{\max }$ or simulations. Furthermore, while other studies have also noted a reduction in size at sex change for harvested species, ours is the first to apply the relative size at sex change invariance hypothesis for a size-selectively harvested intertidal invertebrate.

One of the most commonly observed indirect effects of size-selective harvesting is a change in individual growth rates (Heino and Godo 2002), which in turn should have a strong effect on size-related traits (Stearns 1992; Heino and Godo 2002), such as the timing of sex change. Thus, understanding how size-selective harvesting affects size at sex change requires knowledge of how growth rates (and age structures/mortality) differ between harvested and nonharvested populations. If growth rates are described by the von Bertalanffy growth (VBG) curve:

$$
\left.L=L_{\max }\left\{1-e e^{-k\left(t-t_{0}\right)}\right]\right\}
$$

(von Bertalanffy 1938), then the expected value of relative size at sex change can be viewed as

$$
L_{50} / L_{\max }=1-e\left[^{-k\left(t^{*-t_{0}}\right)}\right]
$$

(Charnov and Skúladóttir 2000), where $k$ is the growth coefficient (the rate of decrease in growth with age), $t^{*}$ is the age at sex change, $t_{0}$ is the theoretical age at length zero, $L_{50}$ is the size at sex change, and $L_{\max }$ is the maximum or asymptotic length of individuals in the population. Therefore, populations sharing approximately the same $L_{50} / L_{\max }$ value should also have a constant $k\left(t^{*}-t_{0}\right)$ (Charnov and Skúladóttir 2000). By measuring all VBG parameters, correlations of growth rates, size, and age structures (and indirectly, mortality) with $L_{50}$ and $L_{50} / L_{\max }$ can be compared across harvested and nonharvested populations. For example, individuals with slower growth rates are predicted to change sex at smaller sizes (Warner 1975; Charnov 1981).

Lottia gigantea is a size-selectively harvested limpet found in rocky intertidal habitats along the California and Baja California coast $\left(\sim 26^{\circ} \mathrm{N}-39^{\circ} \mathrm{N}\right)$. Like other mollusks that can change sex, L. gigantea is a protandric hermaphrodite (Wright and Lindberg 1982; Wright 1988); individuals of this species start their reproductive life as a male and change sex to female as they grow older and larger. Thus, size-selective harvesting of this species can preferentially remove the large and older females from populations. A number of studies have shown that such harvesting has reduced the mean and maximum size of individuals in affected populations (Pombo and Escofet 1996; Lindberg et al. 1998; Kido and Murray 2003; Roy et al. 2003; Sagarin et al. 2007), but the effects of such size reduction on the life history of this species have not been explored. The theory discussed above predicts that selective removal of the large individuals should reduce the size at sex change of exploited L. gigantea populations, and the relative size at sex change should be approximately constant across populations. We use four different approaches to evaluate these predictions: (i) examining the covariation between $L_{50} / L_{\max }$ and other traits considered to be of general importance to life history (e.g., mean body size and age across populations), as suggested by several authors (Nee et al. 2005; Munday et al. 2006; Savage et al. 2006); (ii) determining whether the observed range of $L_{50} / L_{\max }$ values is a particularly constrained subset of biologically relevant values of this trait; (iii) testing whether observed versus expected values (based on growth rates) of $L_{50} / L_{\max }$ are significantly different; and (iv) comparing the $L_{50}$ of populations with growth rates, with the prediction that slower growth rates lead to smaller $L_{50}$ values.

\section{Material and Methods}

\section{Field Sites}

We sampled a total of 10 sites (populations) from California for this study and categorized sites according to harvest pressure (i.e., high vulnerability to harvest or notharvested/minimally harvested) based on our field observations and previous work on Lottia gigantea (Roy et al. 
2003; Sagarin et al. 2007; Fenberg and Rivadeneira 2011). Three of our sites (Cabrillo National Monument [CNM], Vandenberg Air Force Base [VBG], and Pebble Beach $[\mathrm{PBL}])$ are characterized as having minimal or no harvesting pressure, and the remaining seven sites are characterized as being subjected to high levels of vulnerability to harvesting pressure (fig. 1; table 1). Of the three sites with no or minimal harvesting pressure, Cabrillo National Monument is a part of the U.S. National Park System and is hence well protected, while the other two have strong restrictions on public access, which minimizes poaching. The field sites range in latitude from $32.6^{\circ} \mathrm{N}$ to $36.5^{\circ} \mathrm{N}$, encompassing the middle portion of the geographic range of $L$. gigantea, which is characterized by high average abundance (Fenberg and Rivadeneira 2011). While each of our sites represents a separate population because they are separated by stretches of unsuitable habitat (i.e., sandy beach), and adults do not migrate from the area where they have settled as juveniles, L. gigantea is a broadcast spawner and previous work suggests that there is considerable gene flow among the sites (Fenberg et al. 2010).

\section{Sampling Design}

We measured size-frequency distributions (SFDs) of $L$. gigantea at each site by laying down 1-m-wide belt transects in areas of suitable habitat. Using calipers, we measured the longest shell length of each individual of $L$. gigantea to the nearest millimeter. We took special care to measure every identifiable individual (i.e., over $\sim 10 \mathrm{~mm}$ ) in each transect in order have an accurate measure of the SFD for each population. We measured between 314 and 977 individuals at each site over the course of 2-3 days during the fall and winter low tides from 2003 to 2006 . We used these data to calculate average shell lengths.

We sampled a subset of the individuals of L. gigantea from the same areas where we collected the SFD data. Because there are no secondary sexual characteristics to differentiate the males and females of this species, we sampled these individuals only during the fall and winter months, when L. gigantea spawn (Daly 1975; Kido and Murray 2003) and gonads can be inspected for eggs or sperm. We intentionally sampled individuals proportionally from the population level SFD (i.e., the mode[s] of

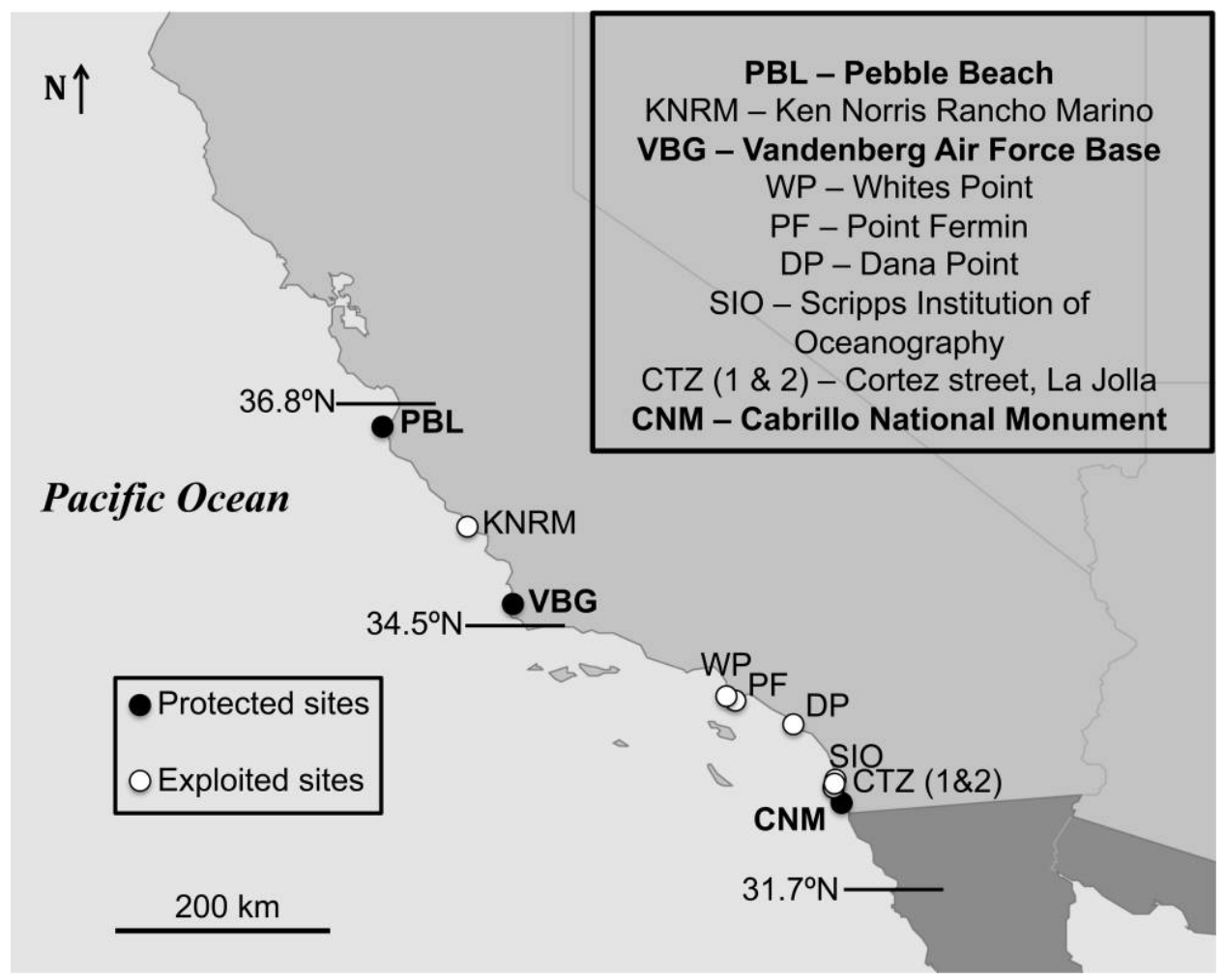

Figure 1: Map of 10 sampled field sites. Sites marked in bold have zero or very minimal harvest pressure. All sites are located within California. Note: the sites listed as CTZ $(1 \& 2)$ are two distinct sampling sites where individuals are separated by a stretch of sandy beach uninhabitable by Lottia gigantea. The access point for these sites is, however, the same. 
Table 1: Demographic and life-history data for 10 Lottia gigantea populations

\begin{tabular}{|c|c|c|c|c|c|c|c|c|c|c|c|c|c|}
\hline Site & $\begin{array}{c}\text { Latitude } \\
\left({ }^{\circ} \mathrm{N}\right)\end{array}$ & $L_{50}$ & $L_{\max }(\mathrm{SE})$ & $t^{*}$ & $k$ & $\%$ female & $\begin{array}{c}\text { Observed } \\
L_{50} / L_{\max }\end{array}$ & $\begin{array}{c}\text { Expected } \\
L_{50} / L_{\max }\end{array}$ & $\begin{array}{c}\text { Mean size } \\
(\mathrm{SE})\end{array}$ & $\begin{array}{c}\text { Mean age } \\
(\mathrm{SE})\end{array}$ & $t_{0}$ & $\begin{array}{c}\text { Age } \\
(L= \\
40 \mathrm{~mm})\end{array}$ & $n$ \\
\hline CNM & 32.66 & 61.4 & $82.0(.44)$ & 8.60 & .163 & .387 & .749 & .765 & $50.0(.57)$ & $7.5(.66)$ & -.292 & 3.81 & 31 \\
\hline CTZ (2) & 32.81 & 54.9 & $69.7(1.7)$ & 8.34 & .143 & .320 & .788 & .742 & $39.1(.88)$ & $6.83(.35)$ & -1.13 & 4.84 & 50 \\
\hline CTZ (1) & 32.82 & 56.5 & $75.0(.54)$ & 9.03 & .144 & .281 & .753 & .761 & $41.9(.68)$ & $6.91(.27)$ & -.92 & 4.37 & 96 \\
\hline SIO & 32.87 & 44.5 & $64.4(.58)$ & 7.28 & .148 & .377 & .691 & .722 & $35.6(.58)$ & $6.98(.40)$ & -1.36 & 5.20 & 69 \\
\hline DP & 33.46 & 39.6 & $52.9(.97)$ & 6.32 & .183 & .367 & .749 & .718 & $27.8(.55)$ & $5.64(.27)$ & -.598 & 7.11 & 49 \\
\hline $\mathrm{PF}$ & 33.70 & 47.0 & $60.4(.62)$ & 6.86 & .157 & .324 & .778 & .747 & $33.6(.46)$ & $5.71(.27)$ & -1.90 & 5.01 & 68 \\
\hline WP & 33.71 & 42.3 & $52.8(.65)$ & 5.39 & .182 & .286 & .801 & .750 & $32.6(.38)$ & $4.42(.26)$ & -2.22 & 5.57 & 63 \\
\hline VBG & 34.73 & 59.9 & $85.6(1.0)$ & 5.94 & .175 & .308 & .700 & .697 & $53.5(1.02)$ & $4.97(.30)$ & -.885 & 2.71 & 39 \\
\hline KNRM & 35.52 & 56.4 & $73.1(.77)$ & 6.52 & .186 & .350 & .772 & .758 & $41.1(.66)$ & $5.13(.29)$ & -1.11 & 3.15 & 60 \\
\hline PBL & 36.56 & 65.6 & $85.8(.69)$ & 7.07 & .199 & .323 & .765 & .766 & $50.4(.97)$ & $6.47(.41)$ & -.236 & 2.92 & 31 \\
\hline
\end{tabular}

Note: The sites in bold have zero or very minimal harvesting pressure. The values of $L_{\max }$ are the average of the largest $5 \%$ of the size-frequency distribution at each site. The values of $k$ and $t_{0}$ were calculated by fitting the von Bertalanffy growth equation through length at age data using nonlinear regression. The $L_{50}$ and $t^{*}$ values were obtained from the logistic regression curves. Expected $L_{50} / L_{\max }$ was calculated using equation $L_{50} / L_{\max }=1-e\left[{ }^{-k\left(t^{*}-t_{0}\right)}\right]$. Age $(L=40$ $\mathrm{mm}$ ) is the age at which individuals reach a length of $40 \mathrm{~mm}$. Full site names are listed in figure 1.

each SFD were sampled proportionally more than the tails, although all size classes over $20 \mathrm{~mm}$ were included in the sampling effort). For our purpose, this is a more appropriate sampling scheme than a purely random sample since it better represents the true distribution of genders across the SFD. We removed 31-96 limpets from the substrate at each site and dissected and examined them for eggs (greenish) or sperm (whitish) in the laboratory. We sampled individuals almost exclusively from substrate with relatively low rugosity in order to minimize the effect of habitat type on growth rates (Kido and Murray 2003). At the three protected sites, we sampled fewer individuals (table 1) than we did at the less protected sites in order to minimize the impact to these populations, which currently harbor the highest concentrations of large individuals (i.e., most fecund) of this species along the mainland California coast. In addition, these protected populations may be an important source of larvae to the less protected areas. Furthermore, the abundance (individuals $\mathrm{m}^{-2}$ ) of L. gigantea tends to be higher at exploited sites compared to protected sites (Fenberg and Rivadeneira 2011), which allowed us to sample more individuals at exploited sites without thinning the population too much. A plot of $L_{50}$ versus sample size $(N)$ across all populations was not significant $(P=.231)$, indicating that sampling was adequate for the purpose of this study.

We determined the predicted size of sex change $\left(L_{50}\right)$ using a logistic regression of categorical variables (male or female) and length, defining $L_{50}$ as the length at which the probability of being female is 0.50 (Hamilton et al. 2007; Linde and Palmer 2008). The overall fit for each regression was significant $(P<.01$; table $\mathrm{A} 1$, available online $)$ and were done in JMP (SAS Institute). We calculated the overall proportion of females at each site to be the number of females/number of males + number of females. In order to avoid sampling juveniles that have no observable sexual characteristics, we restricted our sampling to individuals $20 \mathrm{~mm}$ or larger.

We estimated the value of $L_{\max }$ for each population using the average of the largest $5 \%$ of the SFD rather than relying on an extreme value based on the largest measured individual. The largest individual in a population can be a numerical outlier from the rest of the SFD and is often physically isolated from other individuals (most commonly observed at exploited sites). In addition, the largest individual in a population does not adequately estimate the maximum size $\left(L_{\max }\right)$ predicted by growth rate measurements using the VBG equation (see below).

\section{Growth Rate and Age Determination}

We measured growth rates of L. gigantea at three separate populations around San Diego, California (Cabrillo National Monument, Scripps Institution of Oceanography, and Cortez Street; see fig. 1), by measuring the lengths of tagged individuals every 2-3 months for 1 year. We quadruple tagged individuals with colored and numbered plastic bee tags (Bee Works) attached to the shells with superglue. Forty-five to 60 individuals across the SFD were tagged at each site. We took special care to include individuals from all size classes greater than $20 \mathrm{~mm}$ and were also careful to limit measurements only to individuals living within the same area $\left(\sim 5 \mathrm{~m}^{2}\right)$ in order to reduce habitat related biases in growth (Wright 1989; Kido and Murray 2003). After 1 year of growth, we used Ford-Walford plots (Walford 1946) of final size $(\mathrm{mm})$ versus initial size $(\mathrm{mm})$ to obtain estimates of the von Bertalanffy parameters $k$ (natural log of the slope of the Ford-Walford plot) and 
$L_{\max }(y$-intercept $/ 1$ - slope $)$. The regressions for each population are tightly correlated (table A2, available online), and this method has been applied successfully in other studies of $L$. gigantea as well as for other limpet species (Daly 1975; Balaparameswara Rao 1976; Branch 1981; Guzman and Rios 1987; Kido and Murray 2003). The estimate of $L_{\max }$ using this method accurately represents the largest sizes obtained at each population (within 7.7 $\mathrm{mm}$ of the average of the largest $5 \%$ of the SFD). In addition, the $k$ values (mean $=0.164, \mathrm{SE}=0.003$ ) are similar to previous estimates for this species, (the mean across three studies that used the same methods [Stimson 1968; Daly 1975; Wright 1985] is 0.176, $\mathrm{SE}=0.02$ ). Using the VBG equation, $\left.L=L_{\max }\left\{1-e e^{-k\left(t-t_{0}\right)}\right]\right\}$, we then plotted growth curves for the tagged populations (fig. A1, available online). One potential limitation of the FordWalford approach in estimating VBG parameters is that the theoretical age at length zero $\left(t_{0}\right)$ cannot be calculated and is therefore usually assumed to be zero. Since individuals settle on the substrate at a very small size and very young age, we assumed that $t_{0}$ is negligible and not significantly different from zero when estimating the VBG parameters for the tagged individuals. We did, however, estimate $t_{0}$ when plotting growth curves for all sampled populations using sclerochronology (see below).

\section{Sclerochronology}

There is a long tradition of using the growth increments in molluscan shells to address ecological, taxonomic, paleobiological, demographic, and life-history questions (Frank 1975; Lindberg 1986; Harrington 1987; Goodwin et al. 2001; Gilman 2007). When shells of L. gigantea are sectioned along the axis of maximum growth (i.e., the longest length), small growth increments can be seen within the $\mathrm{M}-1$ layer of the shell (see fig. A2, available online, and MacClintock 1967 for definitions of patellogastropod shell layers and microstructure). Shells from individuals collected at the three San Diego sites (see above) were sectioned along their longest length using a Buehler Isomet low-speed saw. We specifically collected these individuals from areas adjacent to where we tagged individuals for estimating growth rates so that growth rates estimated from the field could be compared to growth rates estimated from sclerochronology. We polished each sectioned shell and recorded the number of growth increments per shell. We recorded the average number of growth increments for two to three separate counts for each shell. A small number of shells were heavily eroded and thus were excluded from the approach because of the difficulty of counting increments near the shell apex. To determine whether the growth increments were laid down annually, semiannually, or more often (e.g., Branch and
Odendaal 2003), we compared a plot of shell size versus the number of growth increments with the growth curve determined for the tagged individuals described above. We found that semiannual (i.e., laid down twice a year) growth increments best fit the predicted growth rate measurements from the tagged individuals (fig. A1). To further confirm this, we compared the average age-specific lengths for each age group (1 year) obtained through sclerochronology analysis (assuming two growth increments per year) with those predicted from the VBG equation for the tagged limpets at each population. We then tested for differences using a paired $t$-test. In addition, we fit a linear regression through the observed versus predicted values and tested whether the slopes are significantly different from 1 . The observed versus predicted values of length at age are not significantly different for the three San Diego populations $(P>.23)$, and regressions of observed versus predicted values are well correlated with slopes not significantly different from 1, indicating that sclerochronology can reliably be used to predict the age of L. gigantea individuals (fig. A1).

After calibration of the sclerochronologic data, we used nonlinear regression to fit the VBG equation through length at age estimated using sclerochronology for each sampled population. When estimating growth curves, we again used the average of the largest $5 \%$ of the SFD as a measure for $L_{\max }$. The observed versus predicted values of length at age were not significantly different for any of the 10 sampled populations $(P>.07)$.

The growth rates estimated from our tagging study as well as using sclerochronology closely match previous estimates for L. gigantea (based on tagged individuals; Daly 1975; Kido and Murray 2003), corroborating the observation that this species can reach ages of approximately 15-18 years at protected populations and approximately 10-13 years at exploited sites in southern and central California. The average $k$ values from the tagged individuals from the three San Diego populations (average $=0.164$; $\mathrm{SE}=0.003)$ are nearly identical to the $k$ values obtained through sclerochronolgy analysis from the 10 sampled populations (average $=0.168 ; \mathrm{SE}=0.006$ )

To determine the age at sex change $\left(t^{*}\right)$ from each population we used the same logistic regression method described above for length at sex change $\left(L_{50}\right)$. Age $t^{*}$ is the age at which the probability of being female is 0.50 (table $1)$. The overall fit for each regression was significant $(P<.01$; table A1). Mean adult age (above 2 years) was then calculated for each population (table 1).

\section{Results}

The SFDs clearly show that the largest size classes are absent at sites where Lottia gigantea are size-selectively 
harvested (fig. A3 and table A3, available online,), a pattern previously documented for this species (e.g., Sagarin et al. 2007). Similarly, body size has also declined over time at exploited sites. For example, the maximum body size of shells from the Palos Verdes peninsula in southern California was more than $90 \mathrm{~mm}$ in 1904 (data from Roy et al. 2003), yet at the same location today, the maximum size we documented is $66 \mathrm{~mm}$ (fig. A4, available online).

Exploited L. gigantea populations consistently change sex at smaller sizes compared to protected populations (fig. 2 ), but the average relative size at sex change across all populations is stable, with a value of approximately 0.754 ; $\mathrm{SE}=0.01$ (range of $L_{50} / L_{\max }$ values $\left.=0.691-0.801\right)$, as predicted by theory (Charnov and Skúladóttir 2000; Gardner et al. 2005; Linde and Palmer 2008). Furthermore, size at sex change $\left(L_{50}\right)$ is highly correlated with maximum body size $\left(L_{\max }\right)$ across sampled $L$. gigantea populations $\left(r^{2}=0.931, P<.0001\right)$; plotted on a log scale, the slope of $L_{50}$ versus $L_{\max }$ is not significantly different from 1 $(0.916 \pm 0.203)$. In addition, $L_{50} / L_{\max }$ is not significantly correlated with either mean body size $(P=.381)$ or mean adult age ( $P=.516$ ) across populations (fig. 3 ), indicating that $L_{50} / L_{\max }$ does not systematically vary across populations with different size and age distributions. The average proportion of females across our populations is 0.332 $(\mathrm{SE}=0.012 ;$ minimum $=0.281$, maximum $=0.387)$ and is not significantly correlated with $L_{50} / L_{\max }(P=$ $.272)$, mean body size $(P=.870)$, maximum body size $(P=.981)$, or mean adult age $(P=.246)$. This bias to- ward the first sex (males in this case) is consistent with theoretical predictions (Charnov and Bull 1989).

The observed values of $L_{50} / L_{\max }$ are a particularly constrained subset of what is biologically possible for $L$. gigantea. Age at maturity $(\alpha)$ for this species is estimated to be approximately 2 years (based on the youngest males in our data set), and sex change can realistically occur 1 year after maturity, so the lower limit to $L_{50} / L_{\max }$ will be at age 3, which corresponds to a value of 0.490 ( $\mathrm{SE}=$ 0.02; averaged across 10 populations). The upper limit to $L_{50} / L_{\max }$ will be at the maximum age recorded for each sampled population, which corresponds to an average of 0.875 ( $\mathrm{SE}=0.01$ ). Therefore, the range of possible values for $L_{50} / L_{\max }$ is much larger $(0.385)$ than the observed range of values (0.11). This constrained range of $L_{50} / L_{\max }$ values along with the lack of systematic covariation between mean age and body size (fig. 3) further supports the prediction that relative size at sex change remains stable across $L$. gigantea populations even under size-selective harvesting and fits the standard definition of life-history invariants (i.e., invariants type A and B of Charnov 1993).

Using only age structure and growth rate data $(k$ and $\left.t^{*}-t_{0}\right)$, the average expected value for $L_{50} / L_{\max }$ across $L$. gigantea populations is 0.743 ( $\mathrm{SE}=0.007$; range of values $=0.697-0.766)$, and the observed versus expected values of $L_{50} / L_{\max }$ do not significantly differ (table 1; paired $t$-test: $P=.205)$. The fact that these values are not significantly different indicates that age structure and growth rate data can reliably be used to predict the observed rel-

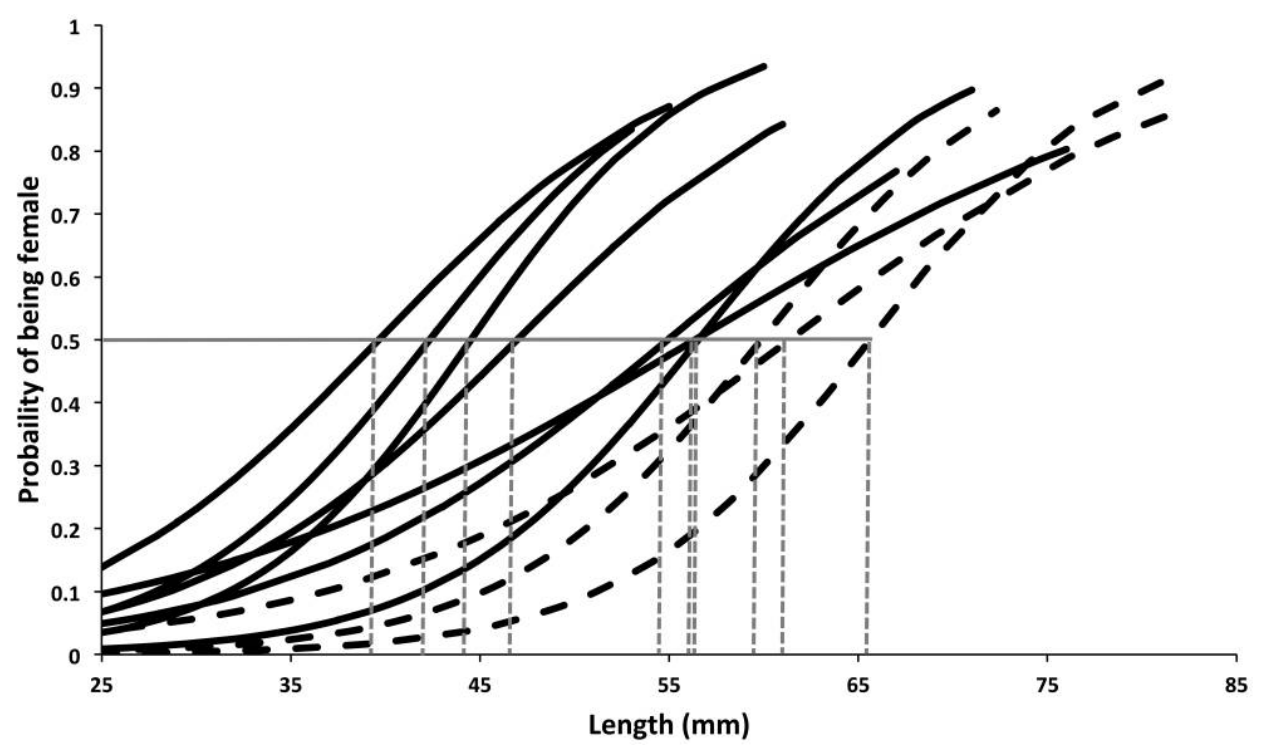

Figure 2: Logistic regression curves for each sampled population. Length $L_{50}$ is the size at which the predicted value for being female is 0.50. The black curves are from exploited populations and the dashed curves are from well-protected populations. 

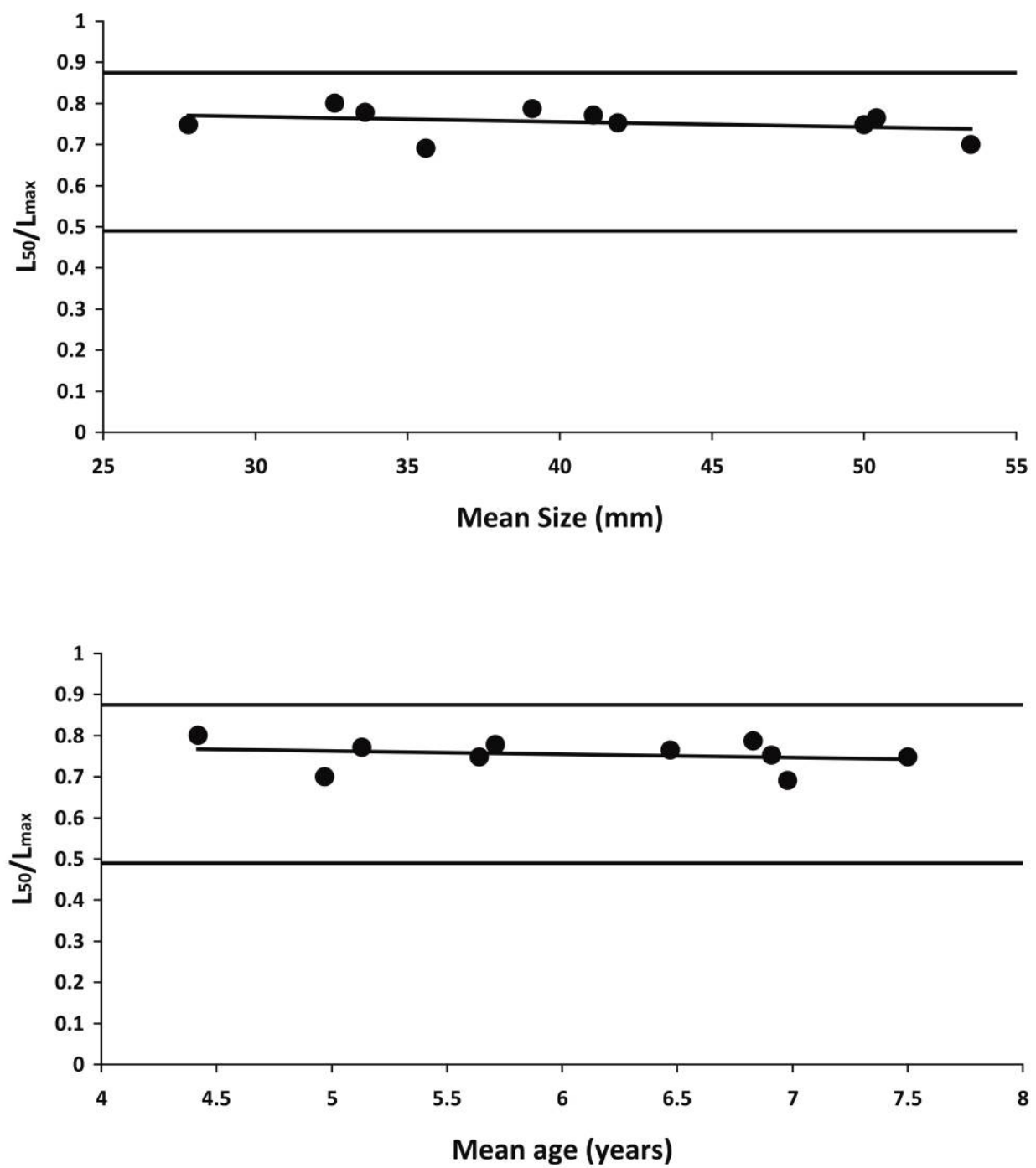

Figure 3: Relative size at sex change $\left(L_{50} / L_{\max }\right)$ for 10 Lottia gigantea populations plotted against mean body size (top) and mean adult age (bottom). The lower solid black lines (0.490) represent the $L_{50} / L_{\max }$ if individuals changed sex at 3 years of age (the earliest plausible age at sex change). The upper solid black lines (0.875) represent the $L_{50} / L_{\max }$ if individuals changed sex at the maximum recorded age for each population. These plots show that $L_{50} / L_{\max }$ are a particularly constrained subset of biologically relevant values that do not vary systematically with either mean body size $(P=.381)$ or mean adult age $(P=.516)$.

ative size at sex change for each population. As predicted by theory (Charnov and Skúladóttir 2000), it also suggests that the product of $k$ and $t^{*}-t_{0}$ is approximately constant $($ mean $=1.36 ; \mathrm{SE}=0.03$; range of values $=1.19-1.45)$, leading to statistically invariant $L_{50} / L_{\max }$ across populations (fig. 3).

The relationship between growth rates and size at sex change is best visualized by plotting $L_{50}$ versus the age at which adults reach a particular size shared by all populations. For example, all populations, regardless of harvest pressure, have an $L_{50}$ of $40 \mathrm{~mm}$ or larger, so the age at 40 $\mathrm{mm}$ can be used to assess the relationship between $L_{50}$ and growth rates across sampled populations. A significant negative correlation of $L_{50}$ by age at $40 \mathrm{~mm}$ indicates that populations that change sex at a larger size also grow at a faster rate $\left(r^{2}=0.807 ; P<.001\right.$; fig. 4$)$.

\section{Discussion}

Size-selective harvesting is increasingly impacting many marine and terrestrial species worldwide, and predicting the biological consequences of such selection pressure re- 


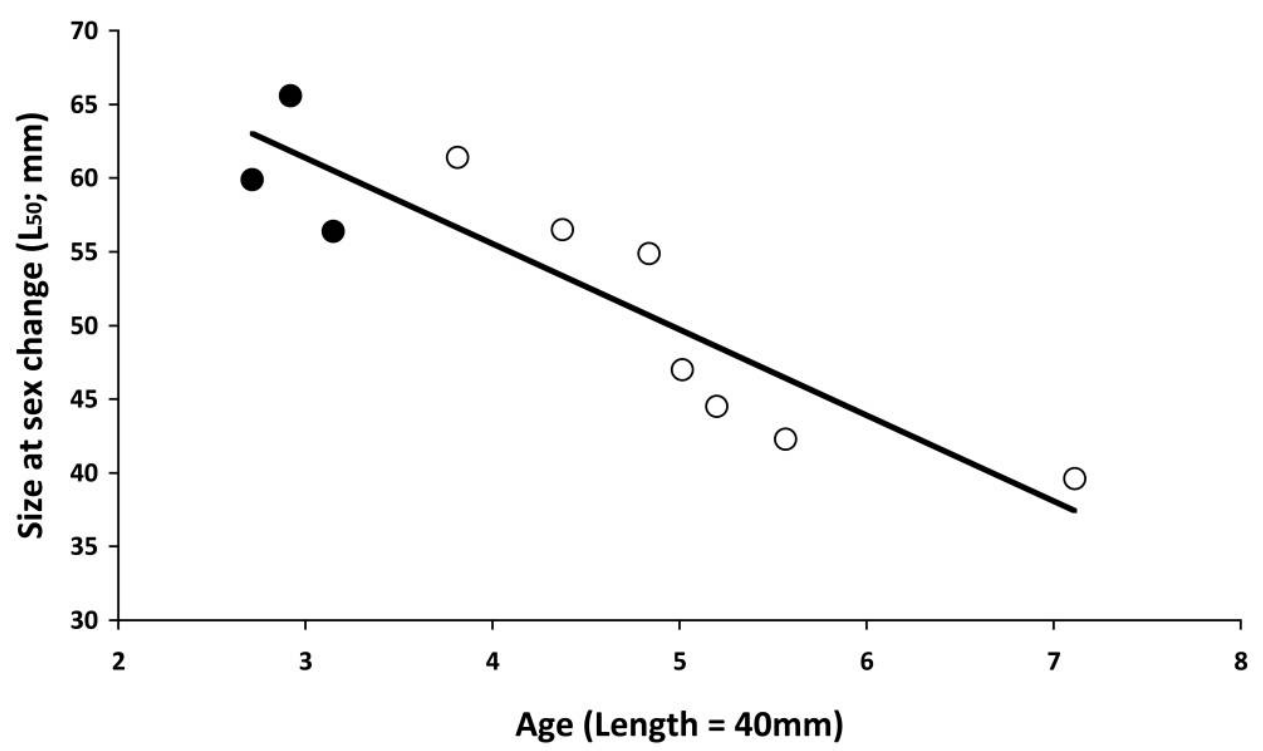

Figure 4: Plot of size at sex change $\left(L_{50}\right)$ versus the age at which individuals reach a length of $40 \mathrm{~mm}$ across 10 Lottia gigantea populations $\left(r^{2}=0.807 ; P<.001\right)$, indicating that populations that change sex at a larger size also grow at a faster rate. Data points with open circles are from exploited populations.

mains a challenge (Fenberg and Roy 2008). However, given adequate demographic and life-history information, it should be possible to predict how populations are likely to respond to such impacts, something that is critical for developing effective conservation and management strategies. Our results show that populations of a sex-changing species (Lottia gigantea) are able to respond to the demographic changes caused by size-selective harvesting by altering their life history in a manner predicted by existing theory (Ghiselin 1969; Warner 1975; Charnov 1981; Charnov and Skúladóttir 2000). Such a labile response indicates that there is not a single optimal size or age for sex change for this species; instead individual plasticity allows populations to maintain a statistically invariant relative timing of sex change (e.g., $L_{50} / L_{\max } \sim 0.75$ ) in response to changes in demography. Although further work is needed on the relative size at sex change across and within species, our results strongly suggest that invariance in the relative timing of sex change can hold intraspecifically for a sizeselectively harvested species.

The primary effect of size-selective harvesting is an overall reduction in body size and an increased mortality rate of affected populations (a pattern commonly observed for marine fish and invertebrates; Fenberg and Roy 2008). While this explains why harvested L. gigantea populations have a lower $L_{\max }$ (maximum size), why $L_{50}$ (size at sex change) should also be reduced is not immediately clear. One of the most commonly cited indirect effects of size- selective harvesting is a change in individual growth rates (Heino and Godo 2002), and any selective pressure influencing growth rates will have a strong effect on size-related traits (Stearns 1992; Heino and Godo 2002), such as the timing of sex change. Size-selective harvest may preferentially remove faster growing individuals that reach a harvestable size at a younger age, leaving individuals with a tendency to grow at a slower rate (Conover and Munch 2002; Conover et al. 2009). If individuals from harvested populations do grow slower, and sex change is under exogenous control (as it is for L. gigantea), then it is expected that the size at sex change $\left(L_{50}\right)$ would be reduced in these populations. As figure 4 shows, populations protected from harvesting pressure not only change sex at a larger size but also grow faster than individuals from exploited populations.

Besides the selective removal of the fastest-growing individuals from a population, other factors affecting growth can also play a strong role. Large individuals of L. gigantea, which are predominantly female, are highly territorial and actively patrol their feeding space (bare rock covered with a thin layer of microalgae), removing both conspecific (usually smaller males) and interspecific intruders (Stimson 1970; Shanks 2002). Selective removal of these individuals vacates their territories for other space competitors to colonize, particularly sessile invertebrates (e.g., mussels and barnacles), macroalgae, and other limpet species (Lindberg et al. 1998). Increased colonization by such 
space competitors may negatively affect the growth rates of $L$. gigantea because these individuals would be less able to increase the size of their home ranges, which is necessary to reach large sizes (Stimson 1970; Lohse 1993). There is also evidence that size-selective harvesting may indirectly increase the total number of $L$. gigantea juveniles and small adults by removing one of their main competitors: territorial females (Fenberg and Rivadeneira 2011). Because growth in L. gigantea is density dependent (Wright 1989), any increase in the number of conspecifics should result in slower overall growth. The combination of these effects (removal of the fastest growers and negative inter- and intraspecific density dependence) will select for slower growth, which can indirectly contribute to a reduced size at sex change $\left(L_{50}\right)$. Finally, size-selective harvesting may have a more direct influence on size at sex change by affecting the mortality schedule of territorial females. For L. gigantea, territory acquisition is considered to be one of the primary mechanisms of sex change (Wright 1989; Shanks 2002). After a harvesting event, the remaining individuals may compete for recently vacated territories and change sex at a smaller size than they normally would if large females were more common (Wright 1988, 1989). A significant negative correlation between size at sex change and total mortality rate $(Z)$ across sampled populations is consistent with this hypothesis $\left(r^{2}=0.59 ; P=.009\right)$; see appendix $B$, available online, for methods and results).

The timing of sex change in L. gigantea and other species is largely dependent on social and demographic cues (Wright 1988; Munday et al. 2006; Rivera-Ingraham et al. 2011), indicating the potential for plasticity in this lifehistory trait in response to changing selection pressure. We suggest that the changes in life history observed here represent a plastic response to harvesting for several reasons. Most notably, neither microsatellite (Fenberg et al. 2010) nor mitochondrial (Dawson 2001; P. B. Fenberg, unpublished data) markers provide evidence of significant genetic differentiation among the populations sampled here; a pattern commonly observed for broadcast spawning marine invertebrates along the California coast (e.g., Dawson 2001; Gruenthal et al. 2007; Addison et al. 2008). Second, although our study ranges across $3.9^{\circ}$ of latitude, the three protected populations are evenly spread across this area and in the case of the Cabrillo National Monument, within $20 \mathrm{~km}$ from the nearest sampled exploited site (fig. 1). Such close proximity to exploited sites without detectable genetic differentiation points to a plastic response to size-selective harvest. Finally, archeological data from the Channel Islands, California dating to at least 10,000 years BP show that harvesting of some L. gigantea populations led to a significant decline in mean and maximum body size of harvested shells through 200 years BP (Erlandson et al. 2011). However, these populations are now fully protected as part of the Channel Islands National Park, and their body sizes have returned to the historically recorded maximum size of this species, upward of 100 $\mathrm{mm}$ (Sagarin et al. 2007; P. B. Fenberg, unpublished data). Taken together, these independent lines of evidence suggest that modern exploited populations may be able to return to their pre-impact state if proper actions are taken to curb harvesting.

The important role played by large and old individuals in maintaining healthy populations and ecosystems cannot be overstated; such individuals tend to be the most fecund and in many cases produce the highest-quality offspring and are effective intra- and interspecific competitors and generally the best predictors of the overall health of populations (Birkeland and Dayton 2005). The response of life-history traits to size-selective harvesting that we report in this study certainly does not diminish the ecological and evolutionary importance of these large individuals. Instead, it shows that life histories of species can be resilient to size-selective harvesting pressure over short timescales, which can provide the time needed to develop effective management strategies. For example, multiple lines of evidence indicate that marine reserves can foster biological recovery of populations (e.g., body size, abundance, biomass, and richness) over short timescales (Lester et al. 2009). On the other hand, from an evolutionary perspective, human harvesting is a relatively new selective force affecting the life histories of many species. The innate plasticity in the life histories that evolved over time to adapt to natural changes in the local environment is now being "tested" by humans on a global scale and across an increasing number of species. How many of these species will be able to maintain viable populations in the face of such pressure remains unclear.

\section{Acknowledgments}

This work was supported by a grant from a National Oceanic and Atmospheric Administration-California Sea Grant (to K.R.) and an EPA Science to Achieve Results (STAR) Fellowship to P.B.F. P.B.F. is grateful for field assistance from A. Calo, B. Fischman, E. Goldberg, B. Igić, S. Menke, B. Pister, and A. Putnam and for valuable conversations with T. Case, P. Dayton, D. Holway, J. Kohn, R. Lande, and D. Lindberg. Comments from two anonymous reviewers substantially improved the manuscript. We would also like to thank the National Park Service and the University of California Reserve System for research permission at Cabrillo National Monument, the Scripps Coastal Reserve, and the Kenneth S. Norris Rancho Marino Reserve. 


\section{Literature Cited}

$\rightarrow$ Addison, J. A., B. S. Ort, K. A. Mesa, and G. H. Pogson. 2008. Rangewide genetic homogeneity in the California sea mussel (Mytilus californianus): a comparison of allozymes, nuclear DNA markers, and mitochondrial DNA sequences. Molecular Ecology 17:42224232.

$\rightarrow$ Allsop, D. J., and S. A. West. 2003a. Changing sex at the same relative body size: similar forces may select for gender switching across taxa in all animals with this facility. Nature 425:783-784.

$\rightarrow-$. 2003b. Constant relative age and size at sex change for sequentially hermaphroditic fish. Journal of Evolutionary Biology 16:921-929.

Alonzo, S. H., and M. Mangel. 2004. The effects of size-selective fisheries on the stock dynamics of and sperm limitation in sex changing fish. Fisheries Bulletin 102:1-13.

Balaparameswara Rao, M. 1976. Studies on the growth of the limpet Cellana radiata (Born). Journal of Molluscan Studies 42:136-144.

von Bertalanffy, L. 1938. A quantitative theory of organic growth. $\rightarrow$ inquiries on growth laws. II. Human Biology 10:181-213.

$\rightarrow$ Birkeland, C., and P. K. Dayton. 2005. The importance in fishery management of leaving the big ones. Trends in Ecology \& Evo lution 20:356-358.

Branch, G. M. 1981. The biology of limpets: physical factors, energy flow, and ecological interactions. Oceanography and Marine $\mathrm{Bi} \rightarrow$ ology: An Annual Review 19:235-380.

$\rightarrow$ Branch, G. M., and F. Odendaal. 2003. The effects of marine protected areas on the population dynamics of a South African limpet, Cym $\rightarrow$ bula oculus, relative to the influence of wave action. Biological Conservation 114:255-269.

$\rightarrow$ Buxton, C. D. 1993. Life history changes in exploited reef fishes or $\rightarrow$ the east coast of South Africa. Environmental Biology of Fishes 36:47-63.

Charnov, E. L. 1981. Sex reversal in Pandalus borealis: effect of a shrimp fishery. Marine Biology Letters 2:53-57.

. 1982. The theory of sex allocation. Princeton University Press, Princeton, NJ.

- 1993. Life history invariants: some explorations of symmetry in evolutionary ecology. Oxford University Press, Oxford.

$\rightarrow$ Charnov, E. L., and J. J. Bull. 1989. Non-fisherian sex ratios with sex change and environmental sex determination. Nature 338:148150.

Charnov, E. L., and R. W. Hannah. 2002. Shrimp adjust their sex ratio to fluctuating age distributions. Evolutionary Ecology Research 4:239-246.

Charnov, E. L., and U. Skúladóttir. 2000. Dimensionless invariants for the optimal size (age) of sex change. Evolutionary Ecology Research 2:1067-1071.

$\rightarrow$ Cipriani, R., and R. Collin. 2005. Life-history invariants with bounded variables cannot be distinguished from data generated by random processes using standard analyses. Journal of Evolutionary Biology 18:1613-1618.

$\rightarrow$ Coleman, F. C., C. C. Koenig, and L. A. Collins. 1996. Reproductive styles of shallow-water groupers (Pisces: Serranidae) in the eastern Gulf of Mexico and the consequences of fishing spawning aggregations. Environmental Biology of Fishes 47:129-141.

$\rightarrow$ Conover, D. O., and S. B. Munch. 2002. Sustaining fisheries yields over evolutionary time scales. Science 297:94-96.

$\rightarrow$ Conover, D.O., S. B. Munch, and S. A. Arnott. 2009. Reversal of evolutionary downsizing caused by selective harvest of large fish.
Proceedings of the Royal Society B: Biological Sciences 276:20152020.

$\rightarrow$ Cowen, R. K. 1990. Sex change and life history patterns of the Labrid, Semicossyphus pulcher, across an environmental gradient. Copeia: 787-795.

Daly, G. 1975. Growth and reproduction in the marine limpet Lottia gigantea (Gray)(Acmaeidae). MS thesis. San Diego State University, San Diego, CA.

Dawson, M. N. 2001. Phylogeography in coastal marine animals: a solution from California? Journal of Biogeography 28:723-736.

$\rightarrow$ Erlandson, J. M., T. J. Braje, T. C. Rick, N. P. Jew, D. J. Kennet, N. Dwyer, A. F. Ainis, R. L. Vellanoweth, and J. Watts. 2011. 10,000 years of human predation and size changes in the owl limpet (Lottia gigantea) on San Miguel Island, California. Journal of Archaeological Science 38:1127-1134.

$\rightarrow$ Fenberg, P. B., M. E. Hellberg, L. Mullen, and K. Roy. 2010. Genetic diversity and population structure of the size-selectively harvested owl limpet, Lottia gigantea. Marine Ecology 31:574-583.

Fenberg, P. B., and M. M. Rivadeneira. 2011. Range limits and geographic patterns of abundance of the rocky intertidal owl limpet, Lottia gigantea. Journal of Biogeography 38:2286-2298.

Fenberg, P. B., and K. Roy. 2008. Ecological and evolutionary consequences of size-selective harvesting: how much do we know? Molecular Ecology 17:209-220.

Frank, P. W. 1975. Latitudinal variation in the life history features of the black turban snail Tegula funebralis (Prosobranchia-Trochidae). Marine Biology 31:181-192.

Gardner, A., D. J. Allsop, E. L. Charnov, and S. A. West. 2005. A dimensionless invariant for relative size at sex change in animals: explanation and implications. American Naturalist 165:551-566.

Ghiselin, M. T. 1969. Evolution of hermaphroditism among animals. Quarterly Review of Biology 44:189-208.

Gilman, S. E. 2007. Shell microstructure of the patellid gastropod Collisella scabra (Gould): ecological and phylogenetic implications. Veliger 48:235-242.

Goodwin, D. H., K. W. Flessa, B. R. Schone, and D. L. Dettman. 2001. Cross-calibration of daily growth increments, stable isotope variation, and temperature in the Gulf of California bivalve mollusk Chione cortezi: implications for paleoenvironmental analysis. Palaios 16:387-398.

$\rightarrow$ Götz, A., S. E. Kerwath, C. G. Attwood, and W. H. H. Sauer. 2008. Effects of fishing on population structure and life history of roman Chrysoblephus laticeps (Sparidae). Marine Ecology Progress Series 362:245-259.

$\rightarrow$ Gruenthal, K. M., L. K. Acheson, and R. S. Burton. 2007. Genetic structure of natural populations of California red abalone (Haliotis rufescens) using multiple genetic markers. Marine Biology 152: $1237-1248$.

Guzman, L. F., and C. F. Rios. 1987. Age and growth of the subAntarctic limpet Nacella (Patinigera) magellanica magellanica (Gmelin, 1791) from the Strait of Magellan, Chile. Veliger 30:159-166.

Hamilton, S. L., J. E. Caselle, J. D. Standish, D. M. Schroeder, M. S. Love, J. A. Rosales-Casian, and O. Sosa-Nishizaki. 2007. Sizeselective harvesting alters life histories of a temperate sex-changing fish. Ecological Applications 17:2268-2280.

Hannah, R. W., and S. A. Jones. 1991. Fishery induced changes in the population structure of the pink shrimp Pandalus jordani. Fishery Bulletin 89:41-51.

Harrington, R. J. 1987. Skeletal growth histories of Protothaca stam- 


\section{The American Naturalist}

inea (Conrad) and Protothaca grata (Say) throughout their geographic ranges, northeastern Pacific. Veliger 30:148-158.

$\rightarrow$ Hawkins, J. P., and C. M. Roberts. 2004. Effects of fishing on sex $\rightarrow$ changing Caribbean parrotfishes. Biological Conservation 115: 213-226.

Heino, M., and O. R. Godo. 2002. Fisheries-induced selection pres $\rightarrow$ sures in the context of sustainable fisheries. Bulletin of Marine Science 70:639-656.

$\rightarrow$ Kido, J. S., and S. N. Murray. 2003. Variation in owl limpet Lottia gigantea population structures, growth rates, and gonadal pro duction on southern California rocky shores. Marine Ecology Progress Series 257:111-124.

Lester, S. E., B. S. Halpern, K. Grorud-Colvert, J. Lubchenco, B. I. Ruttenberg, S. D. Gaines, S. Airame, and R. R. Warner. 2009. Biological effects within no-take marine reserves: a global synthesis. Marine Ecology Progress Series 46:743-751.

Lindberg, D. R. 1986. Name changes in the Acmaeidae. Veliger 29: $142-148$.

$\rightarrow$ Lindberg, D. R., J. A. Estes, and K. I. Warheit. 1998. Human influences on trophic cascades along rocky shores. Ecological Applications 8:880-890.

$\rightarrow$ Linde, M., and M. Palmer. 2008. Testing Allsop and West's size a sex change invariant within a fish species: a spurious ratio or a useful group descriptor? Journal of Evolutionary Biology 21:914917.

$\rightarrow$ Lohse, D. P. 1993. The importance of secondary substratum in a rocky intertidal community. Journal of Experimental Marine Biology and Ecology 166:1-17.

MacClintock, C. 1967. Shell structure of patelloid and bellerophontoid gastropods (Mollusca). Peabody Museum of Natural History Bulletin 22:i-140.

McGovern, J. C., D. M. Wyanski, O. Pashuk, C. S. Manooch, and G. R. Sedberry. 1998. Changes in the sex ratio and size at maturity of gag, Mycteroperca microlepis, from the Atlantic coast of the southeastern United States during 1976-1995. Fishery Bulletin 96: 797-807.

$\rightarrow$ Molloy, P. P., M. J. Paddack, J. D. Reynolds, M. J. G. Gage, and I. M. Côté. 2010. Relative size-at-sex-change in parrotfishes across the Caribbean: is there variance in a supposed life-history invariant? Evolutionary Ecology 25:429-446.

$\rightarrow$ Munday, P. L., P. M. Buston, and R. R. Warner. 2006. Diversity and flexibility of sex-change strategies in animals. Trends in Ecolog: \& Evolution 21:89-95.

$\rightarrow$ Nee, S., N. Colegrave, S. A. West, and A. Grafen. 2005. The illusion of invariant quantities in life histories. Science 309:1236-1239.

$\rightarrow$ Platten, J. R., I. R. Tibbetts, and M. J. Sheaves. 2002. The influence of increased line-fishing mortality on the sex ratio and age of sex reversal of the Venus tusk fish. Journal of Fish Biology 60:301318.

Pombo, O. A., and A. Escofet. 1996. Effect of exploitation on the limpet Lottia gigantea: a field study in Baja California (Mexico) and California (U.S.A.). Pacific Science 50:393-403.

Reznick, D. N., and C. K. Ghalambor. 2005. Can commercial fishing cause evolution? answers from guppies (Poecilia reticulata). Canadian Journal of Fisheries and Aquatic Sciences 62:791-801.

Rivera-Ingraham, G. A., F. Espinosa, and C. García-Gómez. 2011. Environmentally mediated sex change in the endangered limpet Patella ferruginea (Gastropoda: Patellidae). Journal of Molluscan Studies 77:226-231.

Roy, K., A. G. Collins, B. J. Becker, E. Begovic, and J. M. Engle. 2003. Anthropogenic impacts and historical decline in body size of rocky intertidal gastropods in southern California. Ecology Letters 6:205211.

Sagarin, R. D., R. F. Ambrose, B. J. Becker, J. M. Engle, J. Kido, S. F. Lee, C. M. Miner, et al. 2007. Ecological impacts on the limpet Lottia gigantea populations: human pressure over a broad scale on island and mainland intertidal zones. Marine Biology 150:399413.

Savage, V. M., E. P. White, M. E. Moses, S. K. M. Ernest, B. J. Enquist, and E. L. Charnov. 2006. Comment on "the illusion of invariant quantities in life histories." Science 312:198.

Shanks, A. L. 2002. Previous agonistic experience determines both foraging behavior and territoriality in the limpet Lottia gigantea (Sowerby). Behavioral Ecology 13:467-471.

Stearns, S. C. 1992. The evolution of life histories. Oxford University Press, Oxford.

Stimson, J. 1968. The population ecology of limpets Lottia gigantea (Gray) and several species of Acmaea (Eschsholtz) coexisting on an intertidal shore. $\mathrm{PhD}$ thesis. University of California, Santa Barbara.

- 1970. Territorial behavior of the owl limpet, Lottia gigantea. Ecology 51:113-118.

Walford, L. 1946. A new graphic method of describing the growth of animals. Biological Bulletin 90:141-147.

$\rightarrow$ Warner, R. R. 1975. Adaptive significance of sequential hermaphroditism in animals. American Naturalist 109:61-82.

Wright, W. G. 1985. The behavioral ecology of the limpet Lottia gigantea: interaction between territoriality, demography, and protandric hermaphroditism. PhD diss. University of California, San Diego.

$\rightarrow \longrightarrow$ 1988. Sex change in the Mollusca. Trends in Ecology \& Evolution 3:137-140.

1989. Intraspecific density mediates sex change in the territorial patellacean limpet Lottia gigantea. Marine Biology 100:353364.

Wright, W. G., and D. R. Lindberg. 1982. Direct observation of sex change in the patellacean limpet Lottia gigantea. Journal of the Marine Biological Association of the United Kingdom 62:737-738.

Associate Editor: Michael G. Neubert Editor: Judith L. Bronstein 